\title{
Cyclic yield strength in definition of design limits for fatigue and creep
}

\author{
Yevgen Gorash $^{1, *}$ and Donald MacKenzie ${ }^{1}$ \\ ${ }^{1}$ Department of Mechanical and Aerospace Engineering, University of Strathclyde, Glasgow G1 1XJ, United Kingdom
}

\begin{abstract}
This study proposes a cyclic yield strength (CYS, $\sigma_{\mathrm{y}}^{\mathrm{c}}$ ) as a key characteristic for the definition of safe design for engineering structures operating under fatigue and creep conditions. CYS is defined on a cyclic stress-strain curve, while monotonic yield strength (MYS, $\sigma_{\mathrm{y}}^{\mathrm{m}}$ ) is defined on a monotonic stress-strain curve. Both values of $\sigma_{\mathrm{y}}^{\mathrm{c}}$ and $\sigma_{\mathrm{y}}^{\mathrm{m}}$ are identified using a 2-steps fitting procedure of the experimental stress-strain curves using Ramberg-Osgood and Chaboche material models. Comparison of $\sigma_{\mathrm{y}}^{\mathrm{c}}$ and fatigue endurance limit $\sigma_{\lim }^{\mathrm{f}}$ on the S-N fatigue curve reveals that they are approximately equal. Hence, basically safe fatigue design is guaranteed in purely elastic domain defined by the $\sigma_{\mathrm{y}}^{\mathrm{c}}$. A typical creep rupture curve in time-to-failure approach for creep analysis has 2 inflections corresponding to the $\sigma_{\mathrm{y}}^{\mathrm{c}}$ and $\sigma_{\mathrm{y}}^{\mathrm{m}}$. These stresses separate 3 sections on the creep rupture curve, which are characterised by 3 different creep fracture modes and 3 creep deformation mechanisms. Thus, basically safe creep design is guaranteed in linear creep domain with brittle failure mode defined by the $\sigma_{\mathrm{y}}^{\mathrm{c}}$. These assumptions are confirmed for several structural low- and high-alloy steels for normal and high-temperature applications.
\end{abstract}

Copyright line will be provided by the publisher

Characterisation of long-term strength of structural materials is an important engineering task for prevention of potential catastrophic failures of critical equipment. However, studies of this type are usually very long-lasting, technically challenging and involve expensive experimental work. Thus, the main scope of this study is the formulation of a simple way to predict characteristics of the long-term material behaviour (creep and fatigue, in the first instance) using basic material properties.

There are several methods to characterise the yield strength $\sigma_{\mathrm{y}}$ that are discussed by Dowling [1]. Here the elastic limit $\sigma_{\mathrm{y}}^{\mathrm{el}}$, defined in the scope of unified Chaboche model [2], is used as $\sigma_{\mathrm{y}}$. This study proposes $\sigma_{\mathrm{y}}^{\mathrm{c}}$ as a key characteristic for the definition of safe design for engineering structures operating under fatigue and creep conditions, as illustrated in Fig. 1. It is defined in context of a cyclic stress-strain curve (SSC), which is obtained from results of cyclic tests for a number of different strain ranges. In the case of steels with a cyclic softening effect, $\sigma_{\mathrm{y}}^{\mathrm{c}}$ separates the low stress range of purely elastic behaviour from moderate stress range of mixed elasto-plastic behaviour. Monotonic yield strength $\sigma_{\mathrm{y}}^{\mathrm{m}}$, which is conventionally defined in context of a monotonic SSC, separates the moderate stress range of mixed elasto-plastic behaviour from the high stress range of purely plastic behaviour. Both values of $\sigma_{\mathrm{y}}^{\mathrm{m}}$ and $\sigma_{\mathrm{y}}^{\mathrm{c}}$ are identified using a 2-steps fitting procedure of the experimental S-S curves. The first step applies the Ramberg-Osgood (R-O) material model, which produces basic smoothing and extrapolation, to the both monotonic and cyclic SSCs separately. The second step of fitting involves a typical rate-independent form of the Chaboche material model with 3 kinematic backstresses $(N=3)$ according to [2]. Fitting the Chaboche model to the both R-O extrapolated SSCs provides the values of $\sigma_{\mathrm{y}}^{\mathrm{m}}$ and $\sigma_{\mathrm{y}}^{\mathrm{c}}$ with minimum offset from the elastic line as $\sigma_{\mathrm{y}}^{\mathrm{el}}$ as follows [2]:

$$
\sigma=\sigma_{\mathrm{y}}^{\mathrm{m}}+\sum_{i=1}^{N} \frac{C_{i}}{\gamma_{i}}\left[1-\exp \left(-\gamma_{i} \varepsilon^{\mathrm{p}}\right)\right] \quad \text { and } \quad \frac{\Delta \sigma}{2}=\sigma_{\mathrm{y}}^{\mathrm{c}}+\sum_{i=1}^{N} \frac{C_{i}}{\gamma_{i}} \tanh \left(\gamma_{i} \frac{\Delta \varepsilon^{\mathrm{p}}}{2}\right),
$$

where the first relation corresponds to monotonic SSC, while second to cyclic SSC having different values of the kinematic hardening constants $\left(C_{i}, \gamma_{i}\right)$. Two sets of constants $\left(C_{i}, \gamma_{i}\right.$ and $\left.\sigma_{\mathrm{y}}\right)$ are identified by automatic fitting equations (1) to the monotonic and cyclic R-O extrapolation. The identification procedure is implemented in Microsoft Excel using an add-in Solver by running an optimisation process, which minimises the difference between R-O and Chaboche stress responses.

Structures operating at normal temperature are usually designed against fatigue failure using stress-life approach. It involves experimental fatigue S-N curves with number of cycles to failure $N^{*}$ vs. stress. Fatigue endurance limit $\sigma_{\lim }^{\mathrm{f}}$ on S-N curve is observed for many structural steels in benign environmental conditions and represents a stress level below which the material does not fail. The comparison of $\sigma_{\mathrm{y}}^{\mathrm{c}}$ defined as material constant and experimental $\sigma_{\mathrm{lim}}^{\mathrm{f}}$ reveals that they are equal as shown in Fig. 1. This assumption is confirmed in [3] on examples of standard low-carbon steel A36 and medium-carbon low-alloy high-strength steel AISI/SAE 4340. Hence, a safe fatigue design is guaranteed in purely elastic domain defined by the $\sigma_{\mathrm{y}}^{\mathrm{c}}$.

Structures operating at high temperature are usually designed against creep failure using time-to-failure approach. It involves experimental creep rupture curves with time to failure $t^{*}$ vs. stress. A typical creep rupture curve is a trilinear smoothed curve in double logarithmic coordinates with 2 inflections corresponding to $\sigma_{\mathrm{y}}^{\mathrm{c}}$ and $\sigma_{\mathrm{y}}^{\mathrm{m}}$. These inflections separate 3 domains on the creep rupture curve, which are characterised by 3 different creep fracture modes - brittle, ductile and mixed (see Fig. 1). Three sections with different creep deformations mechanisms can be typically observed on the minimum creep strain rate curve, which is also a trilinear smoothed curve in double logarithmic coordinates. The deformations mechanisms (linear creep, power-law creep and power-law breakdown) are separated by the same 2 transition stresses (see Fig. 1). This assumption is confirmed in [3] on example of heat resistant high-alloy martensitic steel ASTM P91 at different temperatures. Hence, a safe creep design is guaranteed in linear creep domain with brittle failure mode, which is also defined by $\sigma_{\mathrm{y}}^{\mathrm{c}}$.

\footnotetext{
* Corresponding author: e-mail yevgen.gorash@strath.ac.uk, phone +44790978 0901, fax +44 1415520775
} 


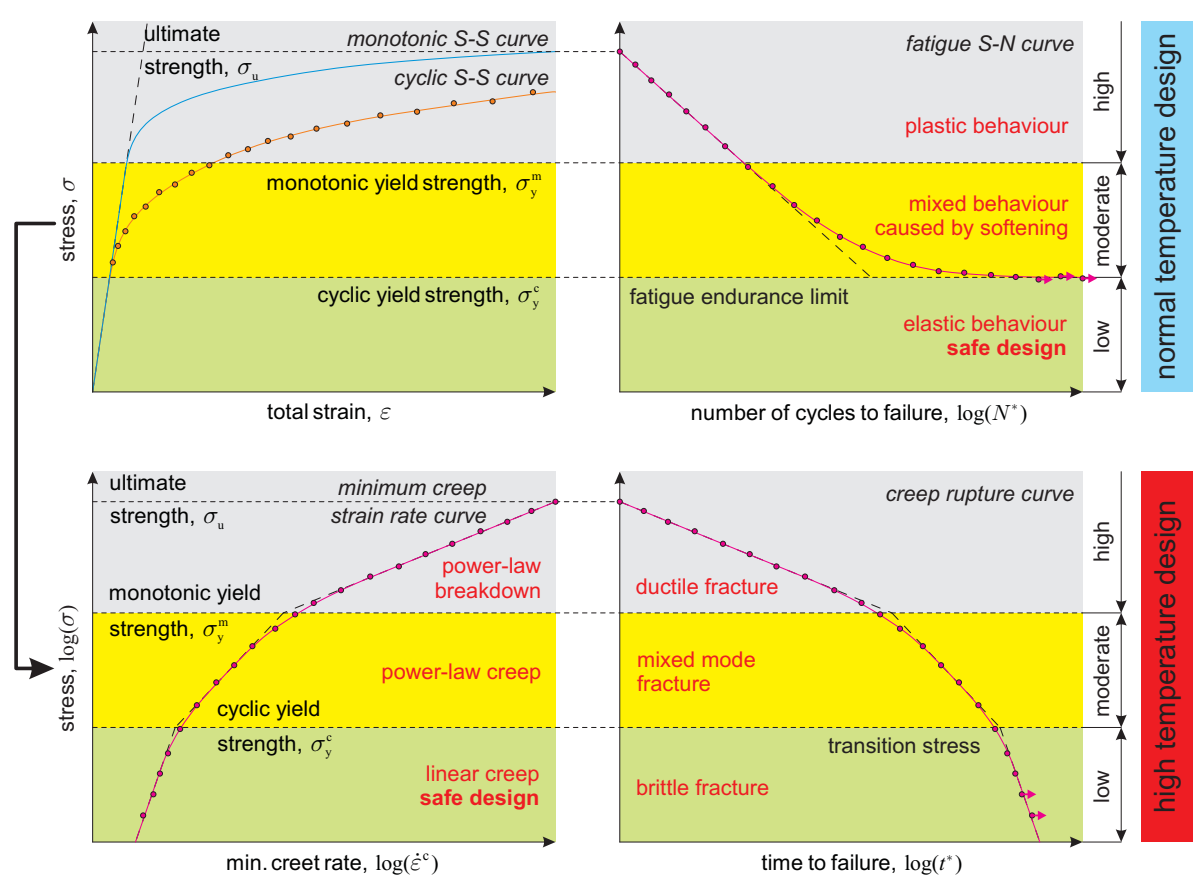

Fig. 1: Concept of the safe structural design for fatigue and creep using cyclic yield strength.
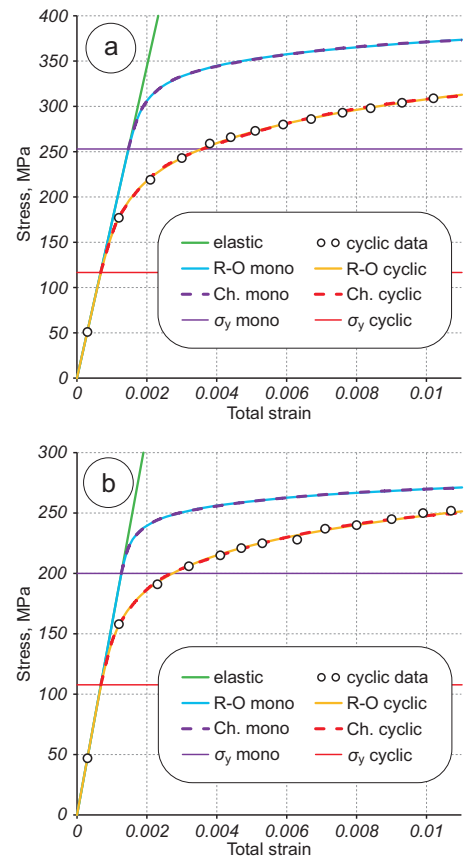

Fig. 2: Fitting of SSCs for P91 steel [4] at $550^{\circ} \mathrm{C}$ (a) and $600^{\circ} \mathrm{C}($ b).

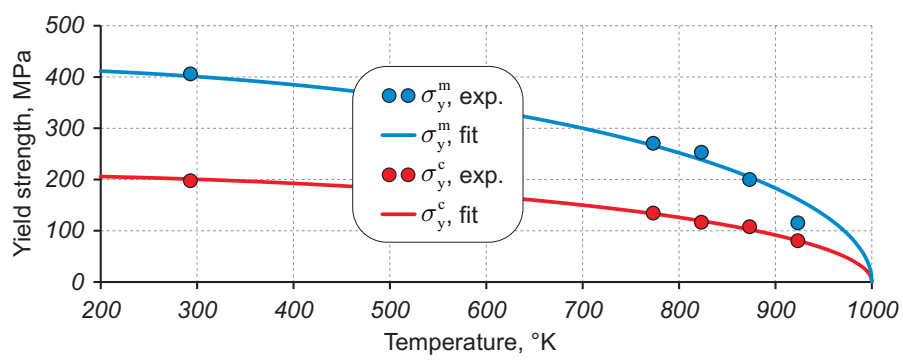

Table 1: Comparison of $\sigma_{\mathrm{y}}^{\mathrm{m}}, \sigma_{\mathrm{y}}^{\mathrm{c}}$ and $\sigma_{\lim }^{\mathrm{f}}$ for P91 steel.

\begin{tabular}{c|ccccc}
\hline Steel & \multicolumn{5}{|c}{ ASTM P91 } \\
\hline Temp., ${ }^{\circ} \mathrm{C}$ & RT & 500 & 550 & 600 & 650 \\
\hline$\sigma_{\mathrm{y}}^{\mathrm{m}}, \mathrm{MPa}$ & 406.1 & 270.7 & 253.0 & 200.0 & 115.3 \\
$\sigma_{\mathrm{y}}^{\mathrm{c}}, \mathrm{MPa}$ & 197.5 & 134.5 & 116.6 & 107.7 & 80.6 \\
$\sigma_{\mathrm{y}}^{\mathrm{m}} / \sigma_{\mathrm{y}}^{\mathrm{c}}$ & 2.1 & 2.0 & 2.2 & 1.9 & 1.4 \\
$\sigma_{\mathrm{lim}}^{\mathrm{f}}, \mathrm{MPa}$ & 418.0 & - & - & - & - \\
$\Delta \sigma, \%$ & 2.8 & - & - & - & - \\
\hline
\end{tabular}

Fig. 3: Elliptic yield surfaces of $\mathrm{P} 91$ steel using $\sigma_{\mathrm{y}}^{\mathrm{m}}$ and $\sigma_{\mathrm{y}}^{\mathrm{c}}$.

The values of $\sigma_{\mathrm{y}}^{\mathrm{m}}$ and $\sigma_{\mathrm{y}}^{\mathrm{c}}$ for P91 steel defined using Chaboche model as shown in Fig. 2 are listed in Table 1. They are plotted versus temperature in ${ }^{\circ} \mathrm{K}$ in Fig. 3. The temperature dependence of a yield strength defined as $\sigma_{\mathrm{y}}^{\mathrm{el}}$ is extrapolated by a simple elliptic equation, which can be considered as an extension of the von Mises yield criterion, in the following form:

$$
\left(\frac{T}{T_{\text {eut }}}\right)^{2}+\left(\frac{\sigma_{\mathrm{y}}}{\sigma_{\mathrm{y} 0}}\right)^{2}=1 \Rightarrow \sigma_{\mathrm{y}}(T)=\sigma_{\mathrm{y} 0} \sqrt{1-\left(\frac{T}{T_{\text {eut }}}\right)^{2}},
$$

where $T_{\text {eut }}=1000^{\circ} \mathrm{K}$ is a typical eutectic temperature for steel alloys; $\sigma_{\mathrm{y} 0}^{\mathrm{c}}=210[\mathrm{MPa}]$ and $\sigma_{\mathrm{y} 0}^{\mathrm{m}}=2 \cdot \sigma_{\mathrm{y} 0}^{\mathrm{c}}=420[\mathrm{MPa}]$ are theoretical yield strengthes at absolute zero temperature for monotonic and cyclic responses correspondingly.

Kimura's [5] assumption of half monotonic yield $\left(\sigma_{\mathrm{y}}^{0.2 \%} / 2\right)$, which corresponds to inflection of creep rupture curves, agrees with the outcomes of the current study, since the relation $\sigma_{\mathrm{y}}^{\mathrm{c}} \approx \sigma_{\mathrm{y}}^{\mathrm{m}} / 2$ is valid for all temperatures according to Table 1 . Equality of $\sigma_{\mathrm{y}}^{\mathrm{m}}$ and $\sigma_{\lim }^{\mathrm{f}}$ at RT can be explained by the concept of gigacycle fatigue [6] introducing two fatigue limits.

The principal advantage of the $\sigma_{\mathrm{y}}^{\mathrm{c}}$ application to the characterisation of fatigue and creep long-term strength is the relatively fast experimental identification. The total duration of all cyclic tests, which are required to reach the stabilised stress response for cyclic SSC is much less than the typical durations of fatigue and creep rupture tests at stress levels around $\sigma_{\mathrm{y}}^{\mathrm{c}}$.

\section{References}

[1] N. E. Dowling, Mechanical Behavior of Materials, 4rd edition (Pearson Education Limited, Harlow, UK, 2013).

[2] J.-L. Chaboche, Int. J. Plasticity 24(10), 1642-1693 (2008).

[3] Y. Gorash and D. MacKenzie, No. ECCC2014-87 (DEStech Publications, Rome, Italy, May 5-7, 2014), pp. 1-12.

[4] NRIM Fatigue Data Sheet No. 78, National Research Institute for Metals, Tokyo, Japan, Dec. 25, 1993.

[5] K. Kimura, No. PVP2013-97819 (ASME, Paris, France, Jul. 14-18, 2013), pp. 1-8.

[6] V.F. Terent'ev, Metal Sci. \& Heat Treatment 50(1-2), 88-96 (2008). 